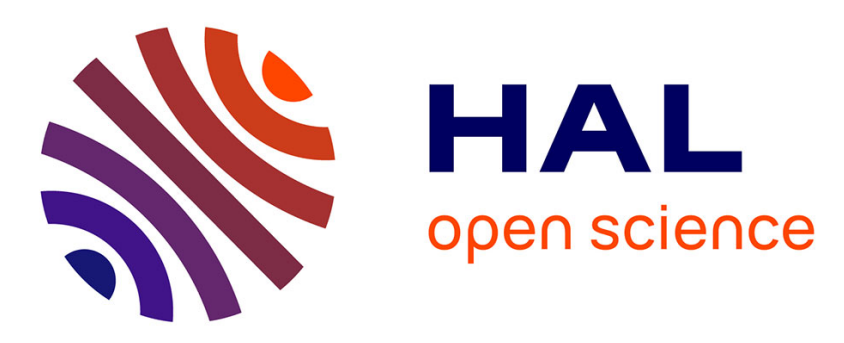

\title{
Joint Tests at INL and CEA of a Transient Hot Wire Needle Probe for In-Pile Thermal Conductivity Measurement
}

\author{
J.-F. Villard, J.-L. Rempe, D.-L. Knudson, J. Liothin, C. Destouches, P. \\ Matheron, T. Lambert, J.-E. Daw
}

\section{To cite this version:}

J.-F. Villard, J.-L. Rempe, D.-L. Knudson, J. Liothin, C. Destouches, et al.. Joint Tests at INL and CEA of a Transient Hot Wire Needle Probe for In-Pile Thermal Conductivity Measurement. ANIMMA 2015 - 4th International Conference on Advancements in Nuclear Instrumentation, Measurement Methods and their Applications, Apr 2015, Lisbonne, Portugal. cea-02500828

\section{HAL Id: cea-02500828 https://hal-cea.archives-ouvertes.fr/cea-02500828}

Submitted on 6 Mar 2020

HAL is a multi-disciplinary open access archive for the deposit and dissemination of scientific research documents, whether they are published or not. The documents may come from teaching and research institutions in France or abroad, or from public or private research centers.
L'archive ouverte pluridisciplinaire HAL, est destinée au dépôt et à la diffusion de documents scientifiques de niveau recherche, publiés ou non, émanant des établissements d'enseignement et de recherche français ou étrangers, des laboratoires publics ou privés. 


\title{
Joint Tests at INL and CEA of a Transient Hot Wire Needle Probe for In-Pile Thermal Conductivity Measurement
}

\author{
J.E. Daw, J.F. Villard, J.L. Rempe, D.L. Knudson, J. Liothin, C. Destouches, P. Matheron, T. Lambert
}

\begin{abstract}
Thermal conductivity is a key property that must be known for proper design, testing, and deployment of new fuels and structural materials in nuclear reactors. Thermal conductivity is highly dependent on the physical structure, chemical composition, and the state of the material. Typically, thermal conductivity changes that occur during irradiation are currently measured out-of-pile using a "cook and look" approach. But repeatedly removing samples from a test reactor to make measurements is expensive, has the potential to disturb phenomena of interest, and only provides understanding of the sample's end state when each measurement is made. There are also limited thermo-physical property data available for advanced fuels; and such data are needed for simulation codes, the development of next generation reactors, and advanced fuels for existing nuclear plants. Being able to quickly characterize fuel thermal conductivity during irradiation can improve the fidelity of data, reduce costs of post-irradiation examinations, increase understanding of how fuels behave under irradiation, and confirm or improve existing thermal conductivity measurement techniques.
\end{abstract}

This paper discusses efforts to develop and evaluate an innovative in-pile thermal conductivity sensor based on the transient hot wire thermal conductivity method (THWM), using a single needle probe (NP) containing a line heat source and thermocouple embedded in the fuel. The sensor that has been designed and manufactured by the Idaho National Laboratory (INL) includes a unique combination of materials, geometry, and fabrication techniques that make the hot wire method suitable for in-pile applications. In particular, efforts were made to minimize the influence of the sensor and maximize fuel hot-wire heating. The probe has a thermocouple-like construction with high temperature resistant materials that remain ductile while resisting transmutation and materials interactions.

THWM-NP prototypes were fabricated for both room temperature proof-of-concept evaluations and high temperature testing. Evaluations have been performed jointly by the INL and the French Alternative Energies and Atomic Energy Commission (CEA), both in Idaho Falls (USA) and in Cadarache (France), in the framework of a collaborative program for instrumentation of

Manuscript received April 2, 2015.

J.E. Daw and, D.L. Knudson are with the Idaho National Laboratory, Idaho Falls, ID 83415 USA (e-mail: joshua.daw@inl.gov).

J.F. Villard, J. Liothin and C. Destouches are with the CEA, DEN, DER, Instrumentation Sensors and Dosimetry Laboratory, Cadarache, F-13108 St Paul-Lez-Durance, France (e-mail: jean-francois.villard@cea.fr).

J.L. Rempe retired from the Idaho National Laboratory and is now with Rempe and Associates, LLC, Idaho Falls, ID, 83404, USA (email: jlrempe@cableone.net)

P. Matheron is with the CEA, DEN, DEC, Uranium Fuels Laboratory, Cadarache, F-13108 St Paul-Lez-Durance, France.

T. Lambert is with the CEA, DEN, DEC, Innovative Fuel Design and Irradiation Laboratory, Cadarache, F-13108 St Paul-Lez-Durance, France.
Material Testing Reactors. Initial tests were conducted on samples with a large range of thermal conductivities and temperatures ranging from $20^{\circ} \mathrm{C}$ to $600{ }^{\circ} \mathrm{C}$. Particularly, tests were recently performed on a sample having thermal conductivity and dimensions similar to UO2 and MOX nuclear fuels, in order to validate the ability of this sensor to operate for in-pile characterization of Light Water Reactors fuels.

The results of the tests already completed at INL and CEA indicate that the Transient Hot Wire Needle Probe offers an enhanced method for in-pile detection of thermal conductivity.

$T$

\section{BACKGROUND}

1 HERMAL properties of materials must be known for proper design, testing, and deployment of new fuels and structural materials in nuclear reactors. In the case of nuclear fuels during irradiation, the physical structure and chemical composition change as a function of time and position within the rod. There are limited available thermal property data for advanced fuels. Such data are needed for simulation design codes that are used in the development of next generation reactors. Being able to quickly characterize fuel thermal conductivity during irradiation can reduce costs from Post Irradiation Examination (PIE), increase understanding of how fuels behave under irradiation, and confirm or improve existing thermal conductivity measurement techniques.

An effort initiated by the Idaho National Laboratory (INL) and Utah State University (USU) investigated the viability of an in-pile thermal conductivity probe based on the Transient Hot Wire Method (THWM), which is an adaptation of the American Society for Testing and Materials (ASTM) needle probe method [1]. The needle probe method is based on the theory of an infinite line heat source applying a constant heat flux to the center of a semi-infinite solid. The probe contains a heating element and a temperature sensor inserted into a material whose thermal conductivity is to be measured. The thermal conductivity is calculated from the thermal response of the sample. Preliminary investigations by INL indicate that this approach may offer advantages over steady state techniques [2].

Recently, through an existing collaboration, INL provided a prototype probe to the French Alternative Energies and Atomic Energy Commission (CEA) for testing of a surrogate fuel material selected to closely match the properties of typical oxide fuels. 
Measuring thermal conductivity of materials in-situ poses significant challenges. Any sensor used in-pile must be robust, as it is subjected to very high temperatures, high pressures, and thermal and fast neutron fluxes. The sensor also must be minimally intrusive, such that it does not affect the measurement.

Historically, fuel thermal conductivity has been measured using either PIE measurements or in pile using a two thermocouple method. Repeatedly removing samples from a test reactor to make out-of-pile measurements during PIE is expensive, has the potential to disturb phenomena of interest, and only provides understanding of the sample's end state at the time each measurement is made. The two thermocouple method uses one or more thermocouples inserted near the center of the fuel rod and one exterior to the fuel (in the coolant or a structure outside the fuel element). Thermal conductivity is derived from the temperature difference between the two thermocouples at steady-state. Currently, the Halden Boiling Water Reactor (HBWR) is the only test reactor where in-pile thermal conductivity measurements are performed for LWR fuel [3]-[6]. The Institute for Energy Technology at Norway's Halden Reactor Project (IFE/HRP) uses this technique to assess the effect of burnup on thermal conductivity. However, this method requires several assumptions, such as uniform fuel composition, uniform fuel density, minimal gap conductance effects, and uniform heat generation in the fuel rod. IFE/HRP tests are typically performed on specially-designed fuel rods with a small asfabricated fuel-to-clad gap to minimize the influence of gap conductance change (densification/swelling, fission gas release) on the fuel centerline temperature during irradiation.

\section{THEORY}

The temperature rise from an internal heat source in a material is dependent on the material's thermal conductivity [7], [8]. In a solid, this method may be applied by embedding a line heat source in the material whose thermal conductivity is to be measured. From a condition of thermal equilibrium, the heat source is energized and heats the sample with constant power. The temperature response of the sample is a function of its thermal properties, and the thermal conductivity is calculated from the temperature rise detected in the sample. Following a brief transient period, a plot of the temperature versus the natural logarithm of time becomes linear, as shown in Fig. 1 (linear region of the time period between times $t_{1}$ and $t_{2}$ and temperatures $T_{1}$ and $T_{2}$ ). The slope of the linear region is used to calculate the test material thermal conductivity.

The needle probe method is based on the theory of an infinite line heat source embedded within a semi-infinite solid. In this configuration, the thermal response is detected by a sensor (such as a thermocouple) located a finite distance from the heat source. The needle probe is designed such that the heat source and thermocouple are both located within the probe. A schematic diagram showing components of a thermal conductivity needle probe is shown in Fig. 2.

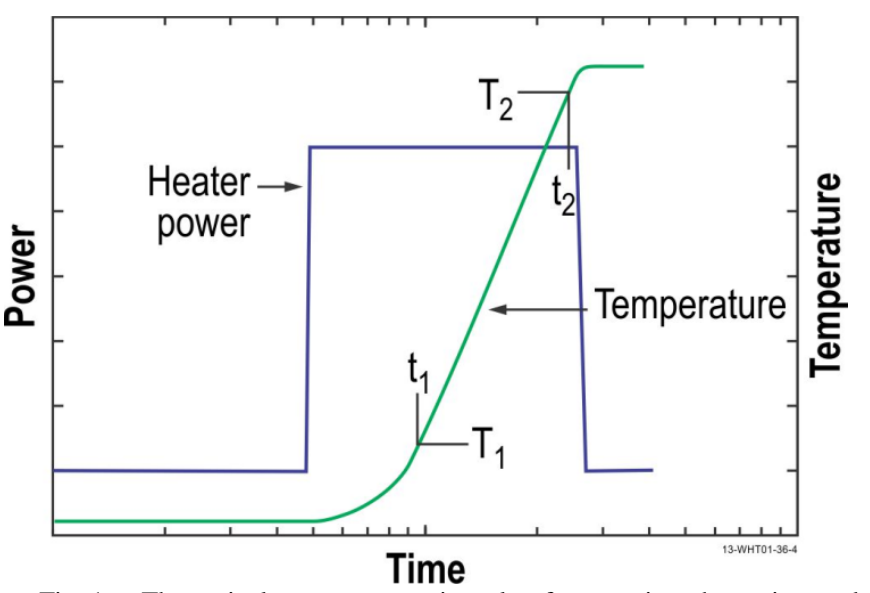

Fig. 1. Theoretical temperature rise plot for transient hot wire probe measurement technique with logarithmic time scale.

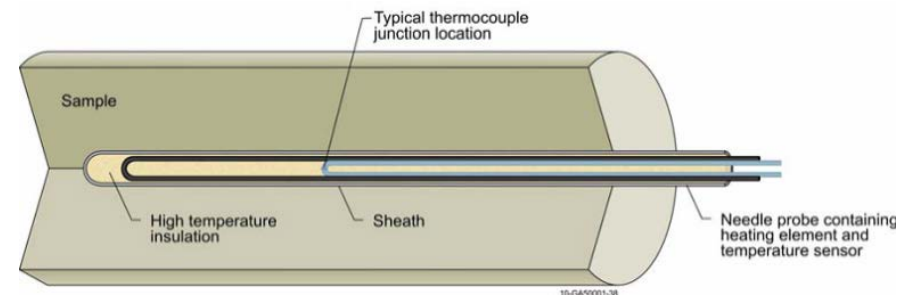

Fig. 2. Configuration of thermal conductivity needle probe installed within cylindrical sample.

The thermal conductivity of the sample material is derived from the slope of the thermal transient using the following relation from the ASTM needle probe testing standard [1]:

$$
\lambda=\frac{C Q}{4 \pi L S}
$$

where $\lambda$ is the thermal conductivity, $C$ is a calibration factor, $Q$ is power dissipated by the heater, $L$ is the heater length, and $S$ is the slope of the linear portion of the transient response. Note that for a small probe (less than $2.5 \mathrm{~mm}$ in diameter) $C$ may be neglected (by assuming it to be unity). As discussed previously (Fig. 1), the slope of the linear section of the transient response is given by:

$$
S=\frac{T_{2}-T_{1}}{\ln \frac{t_{2}}{t_{1}}}
$$

\section{CONSTRUCTION}

Needle probe construction was based on information provided in ASTM D 5334-08 [1]. As specified in this standard, a heating element consisting of a wire loop is contained within a sheathed probe. The heating element is connected to a power supply, which is regulated to provide constant power in the element. The probe also contains a thermocouple with the junction positioned at the mid-point of the heating element.

As previously discussed, thermal conductivity of a sample can be calculated using the power dissipated by the heating 
element (which requires knowledge of the heating element current and voltage drop) and the temperature response of the sample. A six wire configuration of the probe was developed as shown in Fig. 3 to enable collection of these required measurements [9]. Specifically, one pair of wires was used for the thermocouple; one pair of wires carries current to the heating element (across a high-precision shunt); and one pair of wires was used to measure the heating element voltage drop.

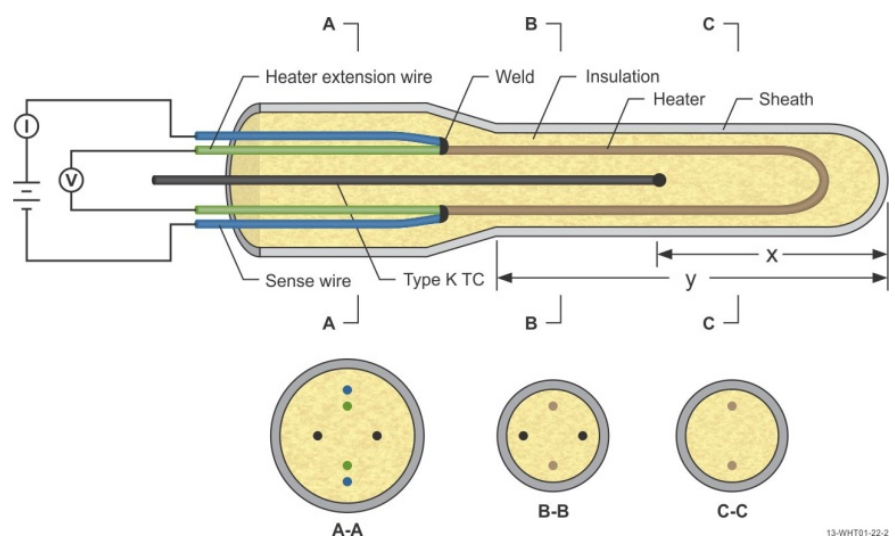

Fig. 3. Thermal conductivity needle probe schematic.

This configuration allows any probe extension length (section A-A in Fig. 3) necessary to extend from the sample to some convenient point (outside a test furnace or above a reactor core, for example). Significantly, the probe extension length (and the unavoidable resistance heating in this extension) is completely inconsequential relative to determination of sample thermal conductivity because current and voltage drop can be measured directly at the heater element.

Materials for the THWM-NP fabricated for this application were selected based on a specified service temperature of $400{ }^{\circ} \mathrm{C}$. Specifically, a 304L stainless steel sheath was used to encase a Type $\mathrm{K}$ thermocouple, a chromel heating element, and copper heater extension wire. Alumina was selected as the electrical insulator. For higher temperature THWM-NP applications, alternate materials may be selected.

With all component materials appropriately loaded, the stainless steel sheath was drawn to an outside diameter of $3.2 \mathrm{~mm}$. Using x-ray inspection techniques, the axial location of heater extension wire junctions was located. The probe portion of the THWM-NP (sections B-B and C-C in Fig. 3) was then swaged to a reduced outside diameter of $2.3 \mathrm{~mm}$. This configuration minimizes the size of the hole required in the sample material (and the associated effects on the accuracy of the measured thermal conductivity).

\section{INITIAL TESTING}

The following section details results of preliminary tests that have been completed at INL to characterize the needle probe method and proposed design for in-core applications. Table I shows data acquired at room temperature for materials of various thermal conductivity values as well as values for each material reported in the literature. Results show that the probe is able to measure thermal conductivity within the range of $0.2-16 \mathrm{~W} \cdot \mathrm{m}^{-1} \cdot \mathrm{K}^{-1}$ with an error of less than $5 \%$ for samples of $50 \mathrm{~mm}$ diameter and $150 \mathrm{~mm}$ length.

\section{TABLE I. RESULTS OF INL EXPERIMENTS CONDUCTED AT ROOM TEMPERATURE}

\begin{tabular}{llll} 
Material & $\begin{array}{c}\text { INL Average } \\
(\mathrm{W} / \mathrm{m} \cdot \mathrm{K})\end{array}$ & $\begin{array}{l}\text { Reported } \\
(\mathrm{W} / \mathrm{m} \cdot \mathrm{K})\end{array}$ & $\%$ Difference \\
\hline Fused Silica & 1.4 & $1.4[10]$ & 0 \\
304L Stainless Steel & 15.9 & $15.3[10]$ & 3.5 \\
Titanium-6\%Al-4\%V & 7.3 & $7.2[11]$ & 1.3 \\
Inconel 625 & 10.3 & $9.9[12]$ & 3.7 \\
Delrin & 0.33 & $0.34[13,14]$ & 2.9 \\
Acrylic & 0.21 & $0.20[15]$ & 5.0
\end{tabular}

Thermal conductivity values for fused silica have also been acquired as a function of temperature. The needle probe data varies from reference data [10] by a maximum of 5.7\%. Tests were also completed to measure the temperature dependent thermal conductivity of several metallic samples. Data collected for $6 \% \mathrm{Al}-4 \% \mathrm{~V}$-Titanium vary from reference data [11] by a maximum of 7.7\%. Data collected for Inconel 625 vary from reference data [12] by a maximum of $7.0 \%$. Data collected for 304-stainless steel vary from reference data [12] by a maximum of $10.0 \%$. The temperature dependent thermal conductivities from INL testing and references are compared in Fig. 4.

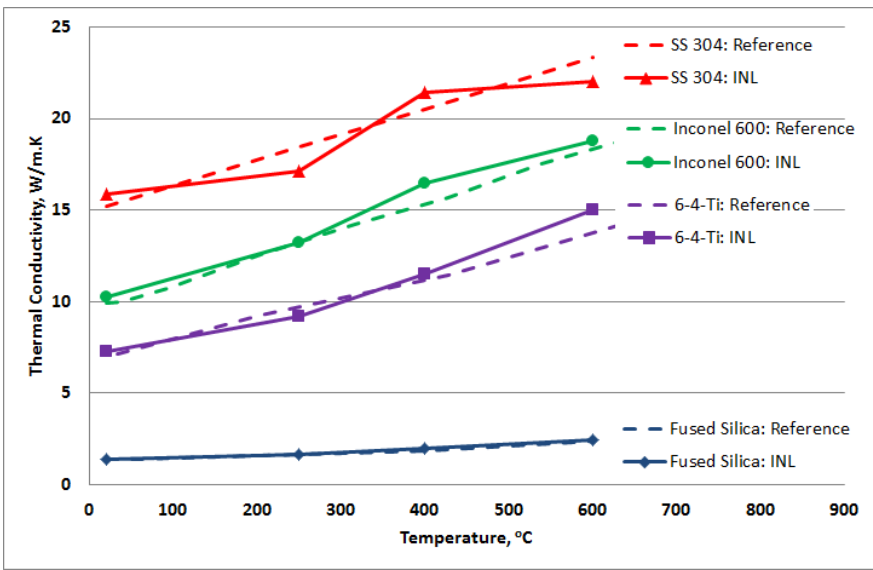

Fig. 4. Experimentally measured and reference thermal conductivities of INL tested samples.

Results of these initial tests show that the THWM-NP is capable of making accurate measurements for samples of sufficient physical size. However, subsequent testing on smaller samples at INL has illustrated that there are difficulties due to thermal coupling between the sample and probe that must be overcome.

\section{BENCHTOP AND IN-FURNACE TESTS AT CEA CADARACHE}

In the framework of a collaborative program between the INL and the CEA for instrumentation of material testing reactors, tests of the THWM-NP have been prepared and performed in the CEA Cadarache center, located in the South of France. 
For the tests at CEA, a material sample having both the same geometry and the same thermal conductivity as a typical PWR fuel rod was requested.

For this reason, we selected a first sample made of Yttriastabilized Zirconia, with a thermal conductivity between 2 and $3 \mathrm{~W} \cdot \mathrm{m}^{-1} \cdot \mathrm{K}^{-1}$, which is similar to PWR fuel thermal conductivity: as shown in Fig. $5, \lambda$ of fresh $\mathrm{UO}_{2}$ is actually between 2 and $3 \mathrm{~W} \cdot \mathrm{m}^{-1} \cdot \mathrm{K}^{-1}$ at $1000^{\circ} \mathrm{C}$, while MOX fuel with $60 \mathrm{GWj} / \mathrm{t}$ burnup has a $\lambda<2.5 \mathrm{~W} \cdot \mathrm{m}^{-1} \cdot \mathrm{K}^{-1}$. In addition, we also selected a second sample made of Alumina and having a higher conductivity (up to $25 \mathrm{~W} \cdot \mathrm{m}^{-1} \cdot \mathrm{K}^{-1}$ ) in order to check the behavior of the probe in this more critical case.

Both samples are cylindrical with $10 \mathrm{~mm}$ external diameter, $2.5 \mathrm{~mm}$ internal diameter, and $150 \mathrm{~mm}$ length (see Fig. 6).

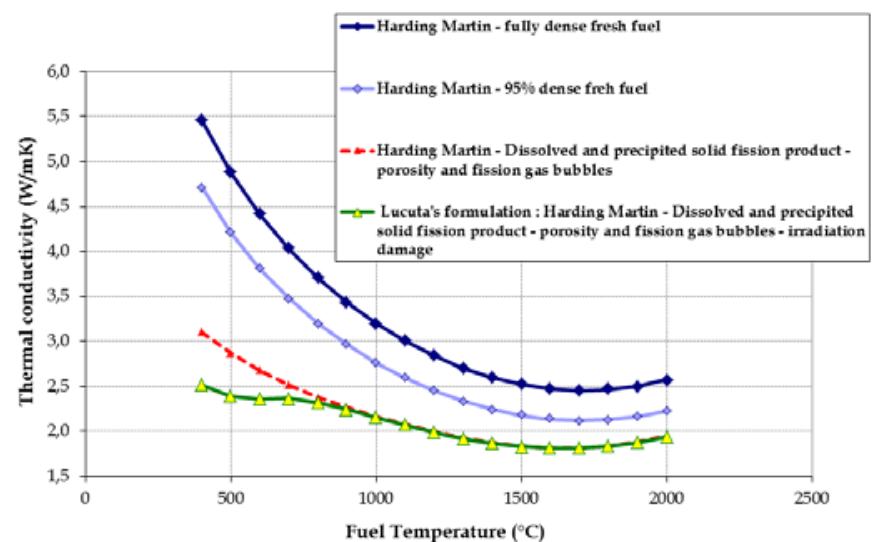

Fig. 5. Thermal conductivity of un-irradiated and irradiated fuels as a function of fuel temperature [16].

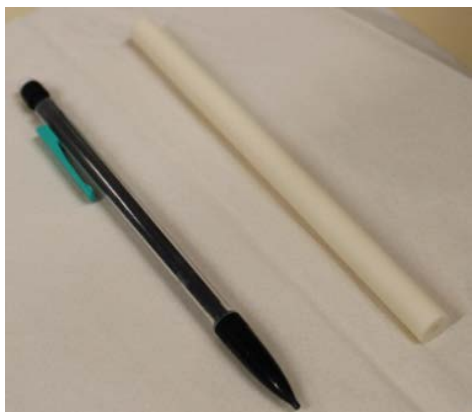

Fig. 6. Example of CEA material samples.

In order to get reference value to compare with THWM-NP measurements, material samples have been characterized by a third part Company. The thermal conductivity $\lambda$ of Yttriastabilized Zirconia and Alumina samples has been evaluated through the measurement of bulk density $\rho$, heat capacity $C_{p}$ and thermal diffusivity $\alpha$ versus temperature $T$ :

$$
\lambda(T)=\rho(T) \cdot C_{p}(T) \cdot \alpha(T)
$$

These reference values are shown in Fig. 7.

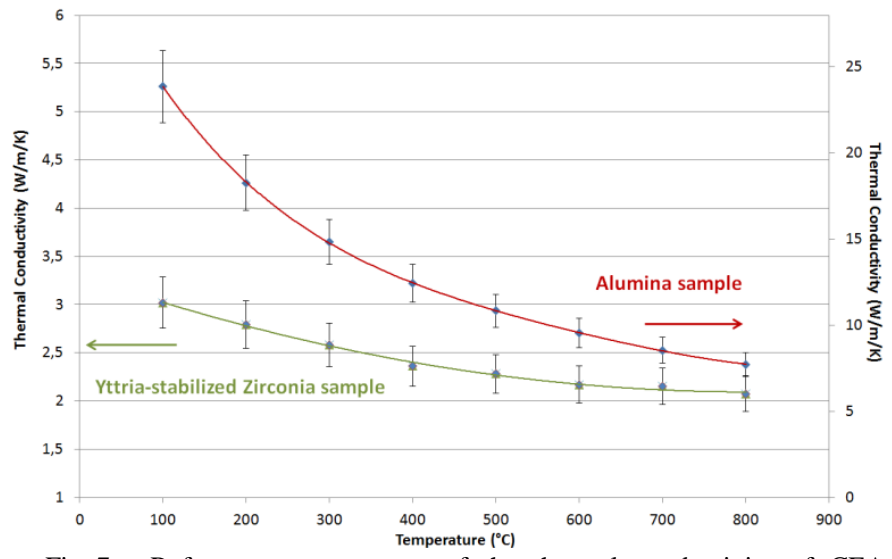

Fig. 7. Reference measurement of the thermal conductivity of CEA material samples.

A specific bench-test has been designed and assembled by the Uranium Fuels Laboratory and the Innovative Fuel Design and Irradiation Laboratory in the $\mathrm{UO}_{2}$-fuel lab in Cadarache.

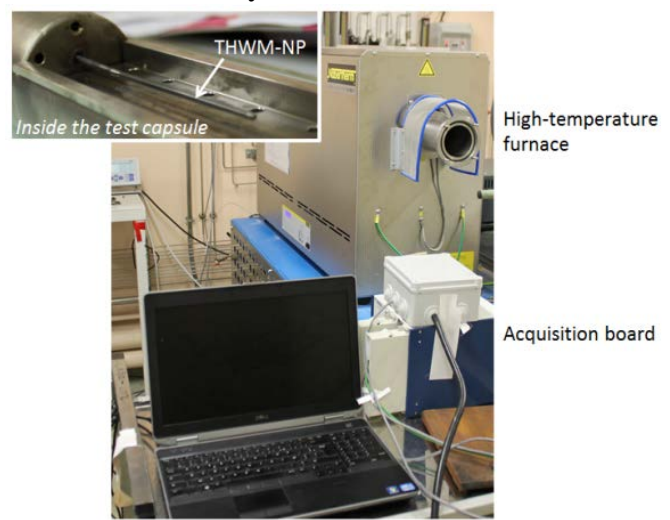

Fig. 8. Picture of the THWM-NP installed in the CEA's bench-test at Cadarache.

The bench-test consists of a stainless steel capsule in which the THWM-NP can be introduced and positioned. The capsule is fed with neutral gas (nitrogen), and can be put in a hightemperature furnace, in order to provide a stabilized temperature around the whole material sample.

As the bench-test has been installed in the $\mathrm{UO}_{2}$-fuel lab, it is also appropriate to perform future tests with real nuclear fuel samples.

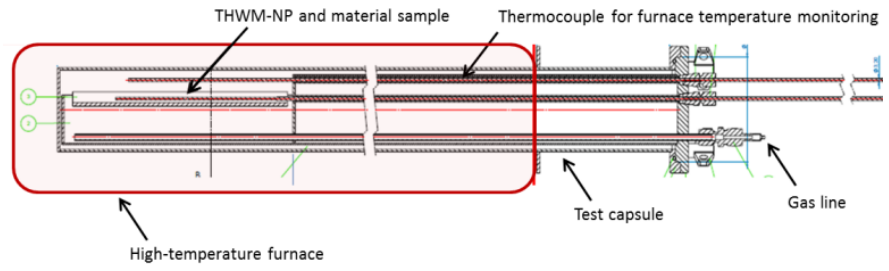

Fig. 9. Schematic drawing of the THWM-NP high-temperature bench-test at CEA.

The bench-test also includes material to control and to monitor the THWM-NP. The system is driven by a National Instrument SCXI acquisition board. Power injection is provided by a Genesys TDK-Lamda power supply, and is detected through the simultaneous measurement of the current 
(using a high-precision shunt) and of the voltage at the THWM-NP heater resistance (see. Fig. 10). All electrical wires are mass-shielded twisted pairs.

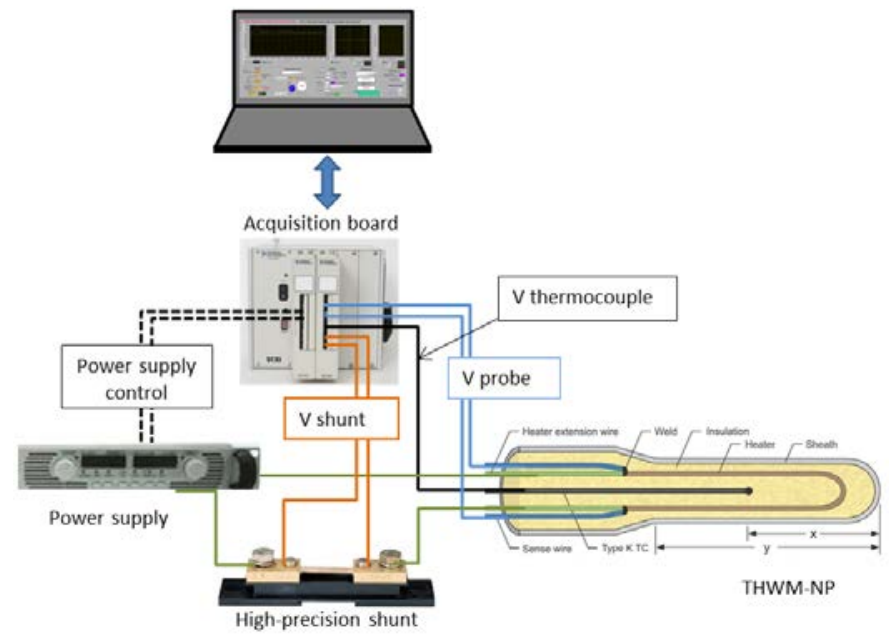

Fig. 10. Electrical connections for THWM-NP tests.

In order to obtain good thermal transfer between the probe and the material sample, a hydro-treated mineral oil with micronized aluminum powder and graphite has been used as thermal coupling. A small amount of the oil has been injected with a syringe in the sample hole, and experience shows that it remains efficient up to $300^{\circ} \mathrm{C}$. Initial tests to perform the THWM-NP measurement without thermal coupling were unsuccessful.

\section{IMPROVEMENTS TO SOFTWARE CONTROL SYSTEM}

The bench-test of the THWM-NP is monitored and set with a computer through a LabVIEW software interface that was prepared by the INL and completed by the CEA. The interface is presented in Fig. 11.

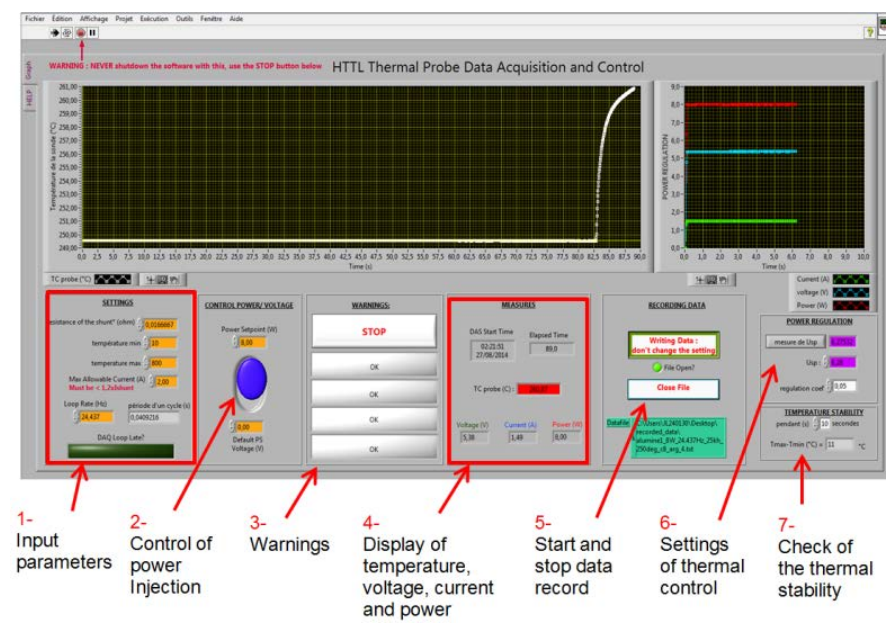

Fig. 11. Interface of the LabVIEW program used for the CEA tests of the THWM-NP.

CEA also developed an additional interface dedicated to online data analysis (see Fig. 12). This interface is activated automatically at the end of a measurement sequence. It displays on the same graph the THWM-NP temperature rise and the thermal conductivity which is calculated online through the slope of the temperature curve. This interface allows the operator to detect immediately the evaluation of the material thermal conductivity.

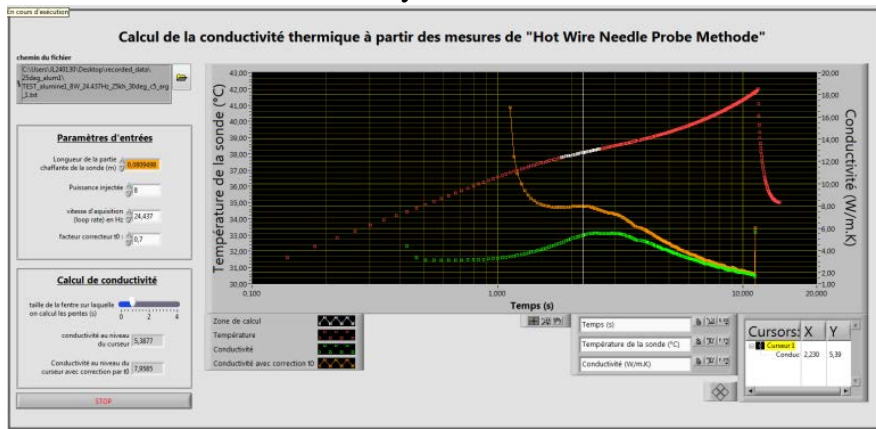

Fig. 12. THWM-NP data analysis interface (temperature rise is in red thermal conductivity is in orange).

It can be observed in Fig. 12 that the duration of the phase where the slope of the temperature curve is linear (white part of the curve) is rather short. In order to get enough measurement points during this phase, the recording rate of the system has been set to $25 \mathrm{kS} / \mathrm{s}$. Data acquisition and data recording have also been synchronized precisely, in order to avoid any error in the calculation of the slope.

The THWM-NP measurement requires a quick rise of the injected power. As the resistance of the heater changes when the temperature increases, the regulation of the power supply has to be adapted rapidly at the beginning of the injection. The original method consisted in increasing the voltage gradually through the power regulation. However, with this method the shorter power rise time that could be reached was $400 \mathrm{~ms}$; furthermore, this rise time was dependent on the regulation parameters chosen by the operator. A new method has been proposed for the power injection: on a first step the value $\mathrm{R}_{0}$ of the heater resistance is measured before the power injection. When the system is switched on at $t_{0}$, the first voltage that is applied directly by the supply is

$$
\mathrm{U}_{0}=\sqrt{P \cdot R_{0}}
$$

where $\mathrm{P}$ is the selected power to be injected. Then the power regulation starts and adjusts the voltage to get the power $\mathrm{P}$ in the probe. With this method, the measured power rise time is $6 \mathrm{~ms}$ and is not operator dependent (see Fig. 13).

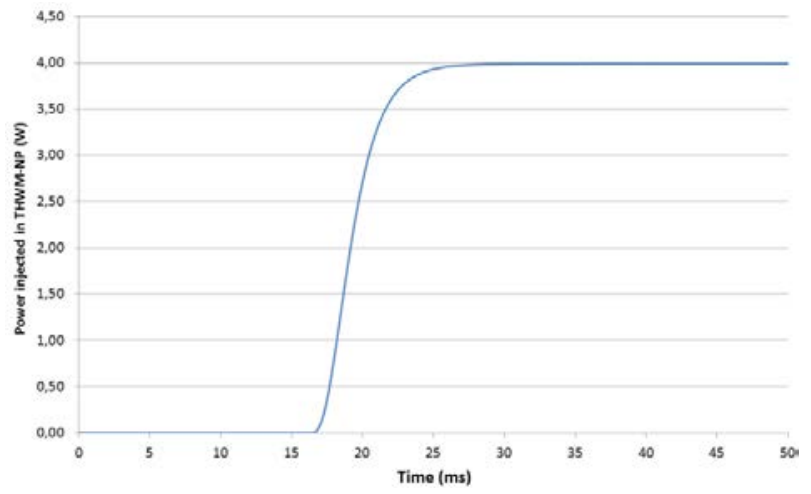

Fig. 13. Power rise in the THWM-NP with optimized injection. 


\section{DISCUSSION OF RESULTS}

The evaluation of the thermal conductivity using the THWM-NP requires the prior determination of the heating time $t_{1}$ which corresponds to the beginning of the material heating [1]. This time depends on the probe geometry and on the thermal coupling between the sensor and the material. In the configuration of the CEA tests, $t_{1}$ was determined by measuring both the Yttria-stabilized Zirconia sample and the Alumina sample with the same probe and the same coupling. As show in Fig. 14, their temperature rise curves separate when the heat reaches the material samples having distinct thermal conductivities. In our case $\mathrm{t}_{1}=0.7 \mathrm{~s}$.

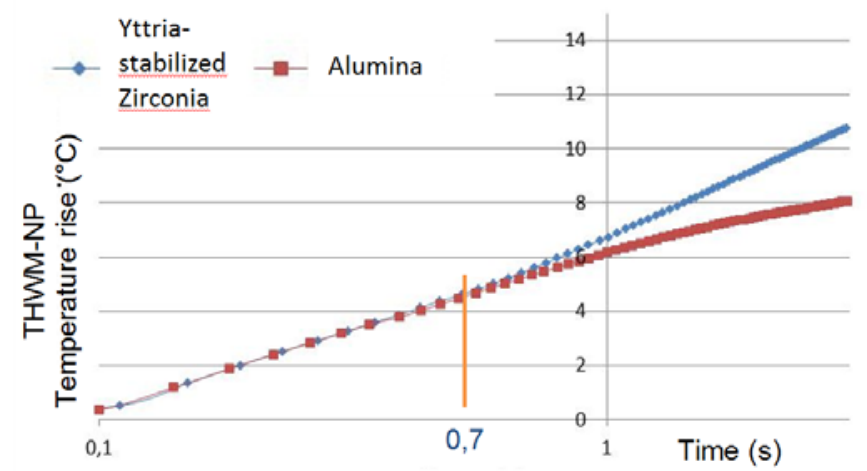

Fig. 14. Measurement of the heating time $t_{1}$ during CEA tests.

High-temperature tests of the THWM-NP have been performed by CEA in July 2014. Despite the small diameter of the sample, the system has proved to be fully operational and to provide the expected measurement with the Yttria-stabilized Zirconia sample.

The repeatability of the measurement has been evaluated: the standard deviation of the stabilized temperature measurement was $0.003^{\circ} \mathrm{C}$, while the standard deviation of the thermal conductivity measurement reached $4 \%$ over the whole tests, but only $0.65 \%$ for successive tests performed without removing the probe from the sample.

The results of these tests are shown in Fig. 15. From room temperature up to $300^{\circ} \mathrm{C}$, THWM-NP measurements indicated a mean thermal conductivity change with temperature of $-2.4 \mathrm{~mW} \cdot \mathrm{m}^{-1} \cdot \mathrm{K}^{-2}$, which is very close to the value given by the reference measurements $\left(-2.2 \mathrm{~mW} \cdot \mathrm{m}^{-1} \cdot \mathrm{K}^{-2}\right)$.

However, a constant bias of about $0.35 \mathrm{~W} \cdot \mathrm{m}^{-1} \cdot \mathrm{K}^{-1}$ has been observed. Even if further investigation has to be conducted to explain this bias, it may be due to the very small diameter of the sample compared to the probe size. Taking into account this observation, the suggestion will be to perform initial calibration measurements when using the THWM-NP in-pile. Finally, these tests demonstrate the ability of the THWM-NP to detect the thermal conductivity change of $\mathrm{UO}_{2}$ and $\mathrm{MOX}$ fuels, which have both similar geometry and thermal conductivity than the Yttria-stabilized Zirconia sample.

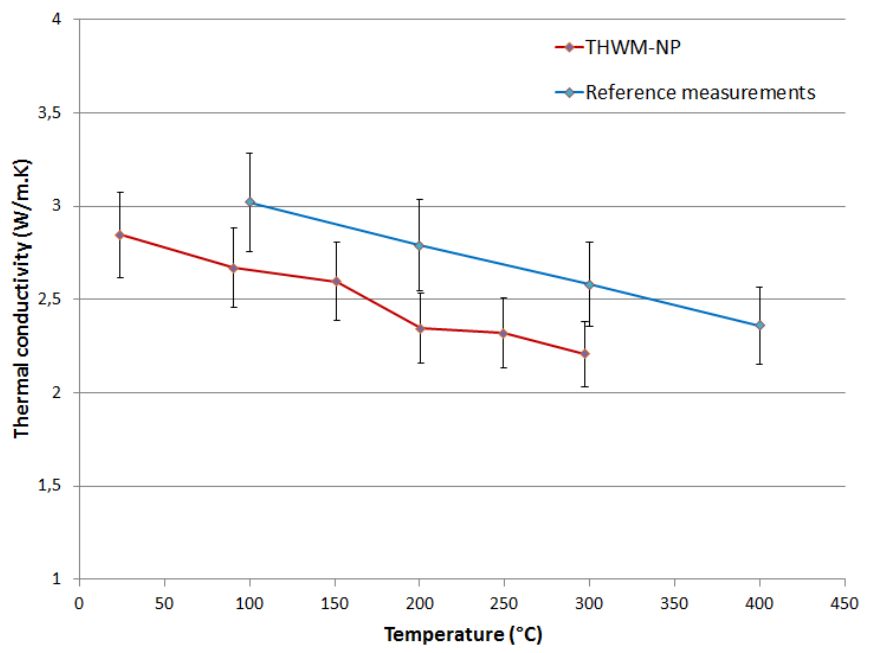

Fig. 15. Result of the THWM-NP tests at CEA with Yttria-stabilized Zirconia sample, compared with reference measurements.

In addition, tests were performed with the Alumina sample but were unsuccessful, as we were unable to detect the appropriate thermal conductivity. We can thus consider that the present design of the THWM-NP is not suitable for measurement of samples with both very small diameter $(10 \mathrm{~mm})$ and high thermal conductivity (above $10 \mathrm{~W} \cdot \mathrm{m}^{-1} \cdot \mathrm{K}^{-1}$ ).

\section{SUMMARY AND DISCUSSION OF FUTURE WORK}

In summary, initial INL and CEA evaluations have demonstrated that the INL-developed THWM-NP can offer an enhanced method for in-pile detection of thermal conductivity. Evaluations provide important insights related to its limitations with respect to sample geometry and the range of applicability for thermal conductivity. In addition, initial testing has also led to important insights related to deployment, such as software enhancements and the need for in-pile calibration. Pending funding availability, future collaborative efforts between CEA and INL will next focus on next in-furnace evaluations of the THWM-NP in unirradiated and irradiated LWR fuel.

In addition, INL plans to participate in an evaluation of the THWM-NP at the Halden Boiling Water Reactor in Norway. Furthermore, INL is developing THWM-NPs that will be used in transient tests at the University of Wisconsin TRIGA facility and ultimately, in INL's Transient Reactor Test Facility (TREAT) when it is restarted.

\section{ACKNOWLEDGMENT}

INL work supported by the US Department of Energy, Office of Nuclear Energy, Science, and Technology, under DOE-NE Idaho Operations Office Contract DE AC07 05ID14517. CEA work supported by the Nuclear Instrumentation Project, Nuclear Energy Division of CEA.

\section{DISCLAIMER}

This information was prepared as an account of work sponsored by an agency of the U.S. Government. Neither the U.S. Government nor any agency thereof, nor any of their 
employees, makes any warranty, express or implied, or assumes any legal liability or responsibility for the accuracy, completeness, or usefulness of any information, apparatus, product, or process disclosed, or represents that its use would not infringe privately owned rights. References herein to any specific commercial product, process, or service by trade name, trademark, manufacturer, or otherwise, does not necessarily constitute or imply its endorsement, recommendation, or favoring by the U.S. Government or any agency thereof. The views and opinions of authors expressed herein do not necessarily state or reflect those of the U.S. Government or any agency thereof.

\section{REFERENCES}

[1] ASTM D 5334 - 08, "Standard Test Method for Determination of Thermal Conductivity of Soil and Soft Rock by Thermal Needle Probe Procedure," Approved 2008.

[2] Rempe, J. L., Condie, K. G., and Knudson D. L., "Thermal Properties for Candidate SCWR Materials,” Tech. Rept. INL/EXT-05-01030, December 2005.

[3] S. Solstad and R. V. Nieuwenhove, "Instrument Capabilities and Developments at the Halden Reactor Project," Presented at the 6th ANS NPIC HMIT 2009 Topical Meeting on Nuclear Plant Instrumentation, Controls, and Human Machine Interface Technology, Knoxville, TN, April 2009.

[4] T. Tverberg, "In-Pile Fuel Rod Performance Characterisation in the Halden Reactor," Technical Meeting on "Fuel Rod Instrumentation and In-Pile Measurement Techniques,” Halden, Norway, September 3-5, 2007.

[5] W. Wiesenack and T. Tverberg, "The OECD Halden Reactor Project Fuels Testing Programme: Selected Results and Plans,” Nuclear Engineering and Design, 207, Issue 2, pp 189-197, 2001.

[6] B. G. Kim, J. L. Rempe, J-F Villard, and S. Solstad, "Review of Instrumentation for Irradiation Testing of Fuels and Materials", invited paper, Nuclear Technology, vol. 176, pp. 155-187, Nov. 2011.

[7] Carslaw, H. S., and Jaeger, J. C., Conduction of Heat in Solids, 2nd ed., Oxford University Press, London, 1959.

[8] Wechsler, A. E., "The Probe Method for Measurement of Thermal Conductivity," in Compendium of Thermophysical Property Measurement Methods, Vol. 2, Recommended Measurement Techniques and Practices, edited by Maglic, K. D., Cezairliyan, A., and Peletsky, V. E., Plenum Press, New York, 1992, pp. 161-185.

[9] “Needle Probe for In-Pile Thermal Conductivity Detection," Patent on October 10, 2012 (ID 13648502, Application S-122190). Inventors: Keith G. Condie, Joy L. Rempe, Darrell L. Knudson, Joshua E. Daw, S. Curtis Wilkins, Brandon S. Fox, and Heng Ban.

[10] Thermal Conductivity, Thermophysical Properties of Matter Vol. 2, edited by Y. S. Touloukian, R.W. Powell, C. Y. Ho, and P. G. Klemens (Plenum, New York, 1970).

[11] “Titanium Alloys Physical Properties," http://www.azom.com/details.asp?ArticleID=1341.

[12] "Nickel-Based Super Alloy Inconel 625 - Properties and Applications by United Performance Alloys," http://www.azom.com/details.asp?ArticleID=4461.

[13] “Common Plastic Molding Design Material Specification," http://www.engineersedge.com/plastic/materials_common_plastic.htm.

[14] “Delrin Acetal Resin Desgin Guide Module III,” http://plastics.dupont.com/plastics/pdflit/americas/delrin/230323c.pdf.

[15] "Polymer Material Properties," http://www.efunda.com/materials/polymers/properties/polymer_datashe et.cfm?MajorID=acrylic\&MinorID=4.

[16] E. Muller, T. Lambert and al., "Thermal Behavior of Advanced $\mathrm{UO}_{2}$ Fuel at High Burnup,” Proceedings of the 2007 International LWR Fuel Performance Meeting, San Francisco, Sept. 30 - Oct. 3, 2007 